\title{
Mitochondrial dysfunction on sinoatrial node and pulmonary vein electrophysiological activities
}

\author{
YUNG-KUO LIN ${ }^{1,2^{*}}$, CHEN-CHUAN CHENG ${ }^{3,4^{*}}$, MIN-CHIEN TSAI $^{5}$, PEI-YU WU ${ }^{5}$, \\ YI-ANN CHEN ${ }^{6}$, YAO-CHANG CHEN ${ }^{5}$, SHIH-ANN $\mathrm{CHEN}^{7}$ and YI-JEN CHEN ${ }^{1,8}$

\begin{abstract}
${ }^{1}$ Division of Cardiovascular Medicine, Department of Internal Medicine, Wan Fang Hospital; ${ }^{2}$ School of Medicine, College of Medicine, Taipei Medical University, Taipei 110; ${ }^{3}$ Division of Cardiology, Chi-Mei Medical Center, Tainan 710; ${ }^{4}$ Department of Internal Medicine, Chung Shan Medical University, Taichung 402; ${ }^{5}$ Department of Biomedical Engineering and Graduate Institute of Physiology, National Defense Medical Center, Taipei 114;
\end{abstract} \\ ${ }^{6}$ Division of Nephrology, Sijhih Cathay General Hospital, New Taipei 221; 7 Division of Cardiology and Cardiovascular \\ Research Center, Taipei Veterans General Hospitals, National Yang-Ming University School of Medicine, Taipei 112; \\ ${ }^{8}$ Graduate Institute of Clinical Medicine, College of Medicine, Taipei Medical University, Taipei 110, Taiwan, R.O.C.
}

Received January 2, 2016; Accepted January 13, 2017

DOI: $10.3892 /$ etm.2017.4285

\begin{abstract}
Atrial fibrillation (AF) is associated with mitochondrial dysfunction. Sinoatrial node (SAN) dysfunction increases arrhythmogenesis of pulmonary veins (PVs), which is the most important trigger of AF; however, it is not clear whether mitochondrial dysfunction differentially regulates electrical activity of SANs and PVs. In the present study, conventional microelectrodes were used to record the action potentials (APs) in isolated rabbit PVs, SANs, left atrium (LA) and right atrium (RA) before and after application of trifluorocarbonylcyanide phenylhydrazone (FCCP; a mitochondrial uncoupling agent) at 10, 100 and $300 \mathrm{nM}$. FCCP application at 100 and $300 \mathrm{nM}$ decreased spontaneous rates in PVs and in SANs at 10, 100 and $300 \mathrm{nM}$. FCCP shortened the 20, 50 and 90\% AP durations in the LA, and shortened only the $20 \%$ AP duration in the RA. FCCP caused a greater rate reduction in SANs than in PVs; however, in the presence of coenzyme- $\mathrm{Q}_{10}$ $(10 \mu \mathrm{M})$, FCCP reduced the beating rate in PVs and SANs to a similar extent. In SAN-PV preparations with intact electrical connections, FCCP (100 nM) application shifted the SAN-PV electrical conduction into PV-SAN conduction in $5(62.5 \%)$ of 8 preparations. In conclusion, mitochondrial dysfunction
\end{abstract}

Correspondence to: Professor Yao-Chang Chen, Department of Biomedical Engineering and Graduate Institute of Physiology, National Defense Medical Center, 161 Sec. 6, Minquan E. Road, Taipei 114, Taiwan, R.O.C.

E-mail: bme02@ndmctsgh.edu.tw

*Contributed equally

Key words: atrial fibrillation, mitochondrial dysfunction, pulmonary vein, sinoatrial node modulates PV and SAN electrical activities, which may contribute to atrial arrhythmogenesis.

\section{Introduction}

Atrial fibrillation (AF), the most common sustained cardiac arrhythmia in clinical practice, is able to induce cardiac dysfunction and strokes (1). Oxidative stress contributes to the genesis of AF (2) and oxidative modifications of proteins are found in chronic AF patients (3). Reactive oxygen species (ROS) may result in abnormal $\mathrm{Ca}^{2+}$ handling and changes in mitochondrial function, leading to arrhythmogenesis (4-8). Mitochondria are key regulators of cardiomyocyte energy metabolism and redox state control (8). Mitochondrial dysfunction-elicited ROS production was proposed as the basis of the mitochondrial free-radical theory of aging (9-12). Evidence indicates that mitochondrial dysfunction may directly alter cardiomyocyte excitability and cell-to-cell coupling through regulating the adenosine monophosphate protein kinase, the adenosine triphosphate-sensitive potassium channel and the sarcolemmal sodium channel (13-16). Furthermore, coenzyme (Co)- $\mathrm{Q}_{10}$, an agent beneficial for mitochondrial function, is widely used to treat heart failure and ischemic heart diseases, which are critical risk factors of AF (17-19). However, it is not clear whether $\mathrm{Co}-\mathrm{Q}_{10}$ has a role in modifying the effects of mitochondrial dysfunction in atrial arrhythmogenesis.

Pulmonary veins (PVs), subsidiary pacemakers, which contain a mixture of working myocardium and pacemaker cells, are an important source of AF initiation and maintenance (20-22). Sinoatrial node (SAN) dysfunction may enhance PV arrhythmogenesis, which may contribute to the high incidence of AF during sick sinus syndrome (23). A previous study has demonstrated that the right and left atria (RA and LA) have different electrical responses to hypoxia and reoxygenation, a condition that may cause mitochondrial dysfunction (24). Therefore, the aim of the present study was to investigate whether mitochondrial dysfunction differentially 
regulates electrical activity between SANs and PVs or between the RA and LA.

\section{Materials and methods}

Ethics statement. The present investigation was approved by the Institutional Animal Care and Use Committee of the National Defense Medical Center (Taipei, Taiwan; IACUC-15-297) and conformed to the institutional Guide for the Care and Use of Laboratory Animals published by the U.S. National Institutes of Health.

Rabbit SAN, PV and atrial tissue preparations. As previously described $(2,23)$, all of the rabbits had ad libitum access to food and water, were maintained in a temperature and humidity-controlled environment $\left(20-22^{\circ} \mathrm{C} ; 50-70 \%\right.$ humidity) with a $12 \mathrm{~h}$ light/dark cycle, and were raised in stainless steel cages. A total of 20 male New Zealand rabbits (Animal Health Research Institute, New Taipei City, Taiwan) weighing 1.5-2.0 kg and aged 3-4 months were anesthetized with an intravenous injection of sodium pentobarbital (100 mg/kg of body weight), followed by an intravenous injection of heparin (1,000 IU/kg of body weight). Subsequently, a midline thoracotomy was performed and the heart and lungs were removed. For dissection of the PVs, the LA was opened by an incision along the mitral valve annulus extending from the coronary sinus to the septum in Tyrode's solution, composed of $137 \mathrm{mM} \mathrm{NaCl}, 4 \mathrm{mM} \mathrm{KCl}, 15 \mathrm{mM} \mathrm{NaHCO}_{3}$, $0.5 \mathrm{mM} \mathrm{NaH}_{2} \mathrm{PO}_{4}, 0.5 \mathrm{mM} \mathrm{MgCl} 2,2.7 \mathrm{mM} \mathrm{CaCl}_{2}$ and $11 \mathrm{mM}$ dextrose. The PV was separated from the atrium at the level of the LA-PV junction and separated from the lungs at the ending of the PV myocardial sleeves. One end of the preparation, consisting of the PV and atrial-PV junction, was pinned with needles to the bottom of a tissue bath. The other end (distal PV) was connected to a Grass FT03C force transducer with a silk thread. The adventitia or epicardial side of the preparation faced upwards. LA and RA tissues were prepared from the LA $(10.0 \times 5.0 \times 0.5 \mathrm{~mm})$ and RA appendages (10.0x5.0x0.5 mm), respectively. For SAN-PV tissue preparations, the SAN with the RA and the right superior PV with the LA were isolated. Tissue preparations were superfused with normal Tyrode's solution and were left to equilibrate for $1 \mathrm{~h}$ prior to electrophysiological study.

Electrophysiological and pharmacological studies. Transmembrane action potentials (APs) of the SAN, PVs, RA and LA were recorded using machine-pulled glass capillary microelectrodes filled with $3 \mathrm{M} \mathrm{KCl}$. Preparations were connected to a WPI model FD223 electrometer under a tension of $150 \mathrm{mg}$. Electrical and mechanical events were simultaneously displayed on a Gould 4072 oscilloscope and Gould TA11 recorder. Signals were digitally recorded with a 16-bit accuracy at a rate of $125 \mathrm{kHz}$. An electrical stimulus with a $10-\mathrm{msec}$ duration and supra-threshold strength was provided by a Grass S88 stimulator through a Grass SIU5B stimulus isolation unit.

For the SAN-PV interaction study, transmembrane APs of the PVs and SANs were recorded within $3 \mathrm{~mm}$ of the distal part of the PV myocardial sleeve and the SAN by simultaneously using machine-pulled glass capillary microelectrodes filled with $3 \mathrm{M} \mathrm{KCl}$, which were connected to a WPI model FD223 electrometer. Tissue was superfused at a constant rate $(3 \mathrm{ml} / \mathrm{min})$ with Tyrode's solution saturated with a $97 \%$ $\mathrm{O}_{2} / 3 \% \mathrm{CO}_{2}$ gas mixture. The temperature was maintained at $37^{\circ} \mathrm{C}$ and the preparations were left to equilibrate for $1 \mathrm{~h}$ prior to initiation of the electrophysiological study. Electrical events were simultaneously displayed on a Gould 4072 oscilloscope and a Gould TA11 recorder. Signals were digitally recorded with a 16-bit accuracy at a rate of $125 \mathrm{kHz}$. Trifluorocarbonylcyanide phenylhydrazone (FCCP; a mitochondrial uncoupling agent) at 10,100 and $300 \mathrm{nM}$ with and without $\mathrm{Co}_{-} \mathrm{Q}_{10}$ (at $10 \mu \mathrm{M}$ ) was perfused for $20 \mathrm{~min}$ to test the pharmacological responses of the PV and SAN in the intact SAN-PV preparation. Spontaneous activity was defined as the constant occurrence of spontaneous APs in the absence of any electrical stimuli.

AP amplitude (APA) was obtained from the resting membrane potential or maximum diastolic potential to the peak of AP depolarization. AP durations (APDs) at repolarization of 20,50 and $90 \%$ of the APA were measured as the $\mathrm{APD}_{20}, \mathrm{APD}_{50}$ and $\mathrm{APD}_{90}$, respectively. Spontaneous activity was defined as the constant occurrence of spontaneous APs in the absence of any electrical stimuli.

Statistical analysis. Data are presented as the mean \pm standard error of the mean. A repeated one-way analysis of variance with post-hoc Tukey's test was used to compare the effects of FCCP on the RA and LA. The effects of FCCP and Co- $\mathrm{Q}_{10}$ on the PV and SAN were compared by a Wilcoxon signed-rank test or a paired t-test, depending on the outcome of the normality test. $\mathrm{P}<0.05$ was considered to indicate a statistically significant difference.

\section{Results}

Effects of FCCP on the electrical activity in isolated PVs and SANs. FCCP (10, 100 and $300 \mathrm{nM})$ significantly decreased the SAN spontaneous rate in a concentration-dependent manner compared with the control $(\mathrm{P}<0.01$; Fig. 1$)$. As exhibited in Fig. 2, FCCP at 100 and $300 \mathrm{nM}$ significantly decreased PV spontaneous rates compared with the control and FCCP at $10 \mathrm{nM}$. In addition, FCCP (100 nM) significantly reduced the beating rate to a greater extent in the SAN than in the PV ( $34 \pm 4.9$ vs. $16.3 \pm 3.2 \% ; n=6 ; \mathrm{P}<0.05$; Fig. 3 ).

In the presence of $\mathrm{Co}-\mathrm{Q}_{10}(10 \mu \mathrm{M})$, as exhibited in Fig. $4 \mathrm{~A}$ and $\mathrm{B}$, FCCP $(100 \mathrm{nM})$ significantly reduced PV spontaneous beating activity $(2.3 \pm 0.2$ to $1.1 \pm 0.4 \mathrm{~Hz} ; \mathrm{n}=5 ; \mathrm{P}<0.05)$ and $\mathrm{SAN}$ spontaneous beating activity $(2.7 \pm 0.2$ to $1.54 \pm 0.3 \mathrm{~Hz} ; \mathrm{n}=6$; $\mathrm{P}<0.05)$ compared with $\mathrm{Co}-\mathrm{Q}_{10}$ alone. In addition, in the presence of $\mathrm{Co}-\mathrm{Q}_{10}$, FCCP $(100 \mathrm{nM})$ reduced the beating rates in the PV and SVN to a similar extent $(51.8 \pm 12.7$ vs. $41.3 \pm 10.5 \%)$ compared with $\mathrm{Co}-\mathrm{Q}_{10}$ alone.

Effects of FCCP in the intact PV-SAN electrical connection. As demonstrated in Fig. 5, FCCP (100 nM) decreased rates in intact SAN-PV preparations; however, FCCP reversed SAN-to-PV electrical conduction to PV-to-SAN conduction in 5 of $8(62.5 \%)$ preparations.

Effects of FCCP on the electrical activities of the RA and LA. As exhibited in Fig. 6, 100 nM FCCP significantly shortened 
A
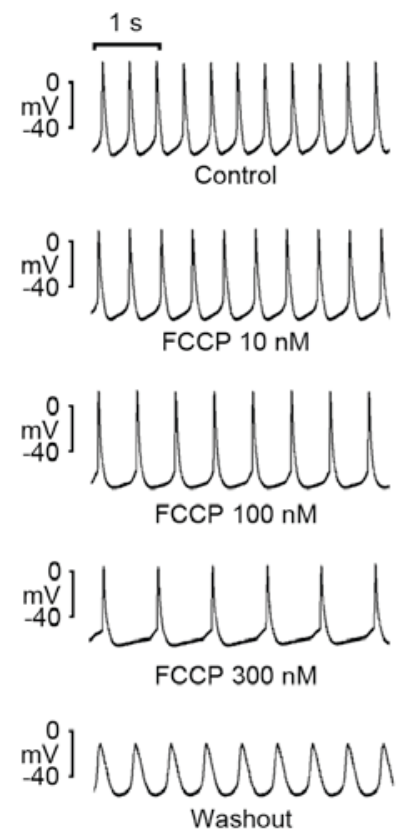

B

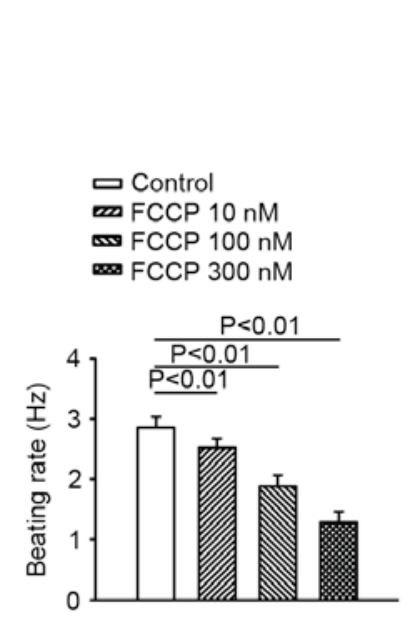

Figure 1. Effects of FCCP on isolated SANs. (A) Effect of application of 10, 100 and $300 \mathrm{nM}$ FCCP on SANs. (B) Average beating rate of SANs before and after FCCP $(10,100$ and $300 \mathrm{nM})$ application. Data are presented as the mean \pm standard error of the mean $(n=6)$. FCCP, trifluorocarbonylcyanide phenylhydrazone; SANs, sinoatrial nodes.

A
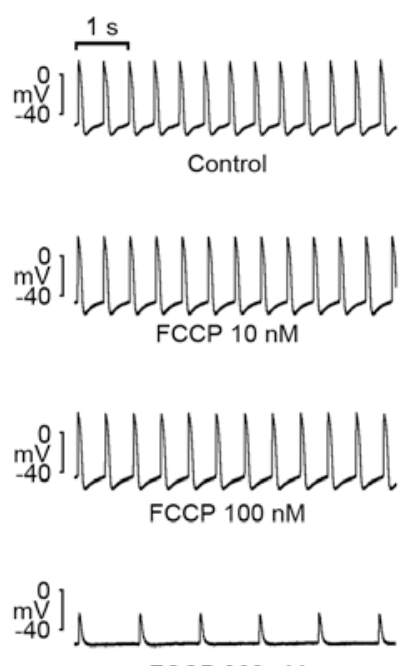

FCCP $300 \mathrm{nM}$

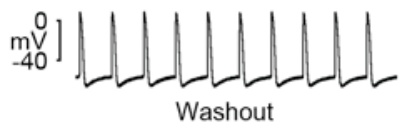

B
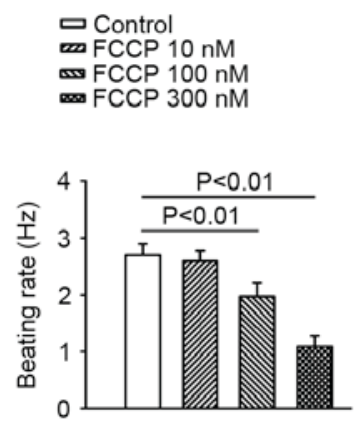

Figure 2. Effects of FCCP on isolated PVs with spontaneous activity. (A) Effect of application of 10, 100 and $300 \mathrm{nM}$ of FCCP on PVs. (B) Average beating rate of PVs with spontaneous activity before and after FCCP $(10,100$ and $300 \mathrm{nM}$ ) application. Data are presented as the mean \pm standard error of the mean $(n=6)$. FCCP, trifluorocarbonylcyanide phenylhydrazone; PVs, pulmonary veins.

the $\mathrm{APD}_{20}, \mathrm{APD}_{50}$ and $\mathrm{APD}_{90}(\mathrm{P}<0.05)$ and decreased the contractility in the LA, whereas $100 \mathrm{nM}$ FCCP only shortened the $\mathrm{APD}_{20}$ to a greater extent in the RA.

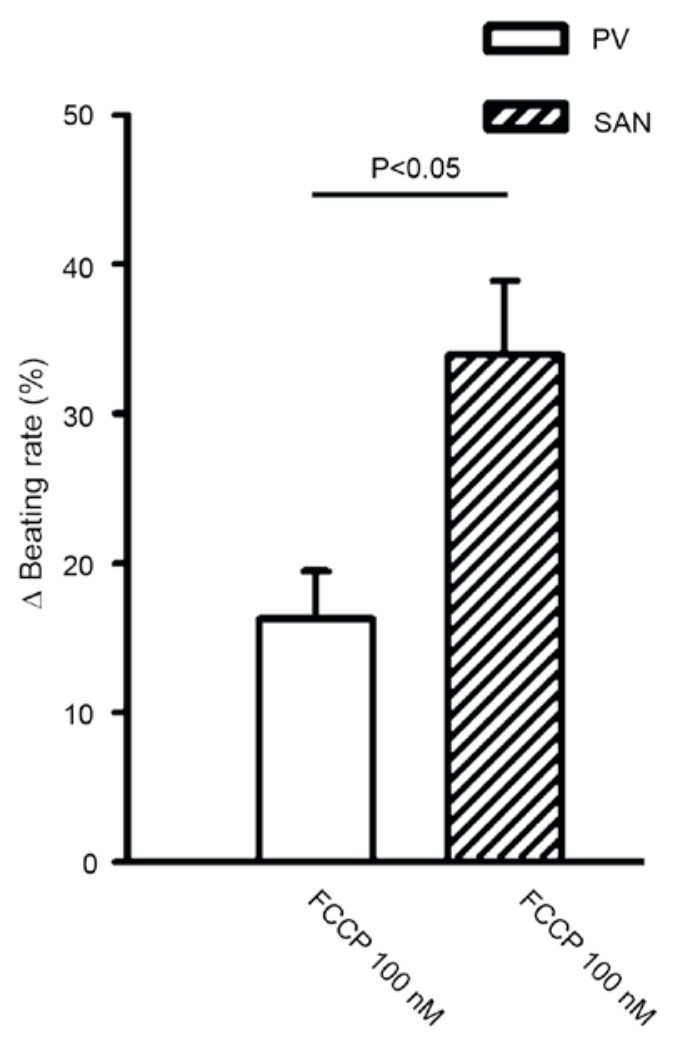

Figure 3. Difference in beating rates before and after $100 \mathrm{nMFCCP}$-application on PVs with spontaneous activity and the SAN. Data are presented as the mean \pm standard error of the mean $(n=6)$. FCCP, trifluorocarbonylcyanide phenylhydrazone; SANs, sinoatrial nodes; PVs, pulmonary veins.

\section{Discussion}

Cardiac mitochondrial function has important roles in cardiomyocyte energy metabolism and redox state control, and has emerged as a target to decrease arrhythmias (6). Hypoxia, which may lead to mitochondrial dysfunction, has been demonstrated to significantly alter cardiac electrophysiology (24). In the present study, it was observed that decreases in PV and SAN spontaneous activities occurred after FCCP treatment, with a high probability of reverse overdrive in $\mathrm{PV}$ and SAN electrical interactions. These findings suggest that mitochondrial dysfunction may modulate PV and SAN electrophysiological properties and enhance PV arrhythmogenesis through a greater reduction of SAN rates.

Hypoxia is able to decrease the rate of spontaneous impulse initiation in SAN fibers by decreasing the slope of diastolic depolarization (25). Similarly, the present study demonstrated that mitochondrial dysfunction is able to decrease PV and SAN spontaneous activities. As mitochondrial dysfunction may lead to an ATP deficiency, the ATP-sensitive potassium $\left(\mathrm{K}_{\mathrm{ATP}}\right)$ channel may subsequently be influenced and remain open, which may lead to decreasing pacemaker activity that is noted in hypoxic conditions.

However, in intact PV-SAN preparations, the present study demonstrated that FCCP $(100 \mathrm{nM})$ altered the electrical conduction from SAN-to-PV to PV-to-SAN, which may have arisen from a greater decrease in SAN rates by FCCP with a resulting overdrive suppression from PVs. This finding suggests an increased vulnerability of SANs to an 
A

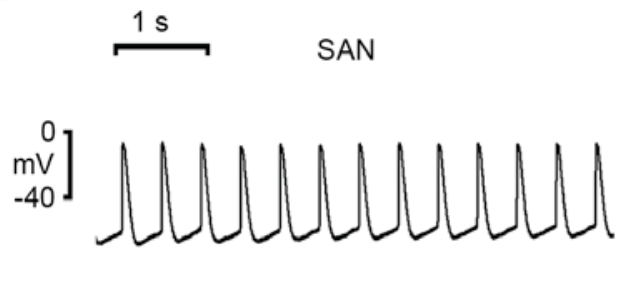

Control

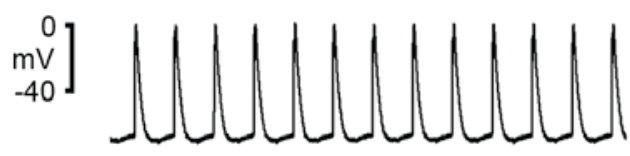

Alcohol

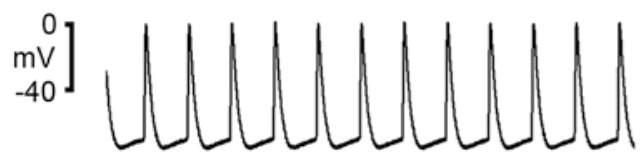

Co- $\mathrm{Q}_{10} 10 \mu \mathrm{M}$

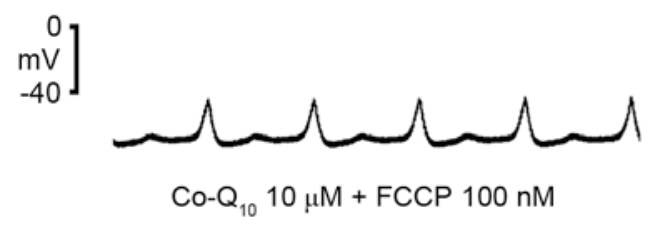

Co-Q $1010 \mu \mathrm{M}$
$\mathrm{Co}-\mathrm{Q}_{10} 10 \mu \mathrm{M}+\mathrm{FCCP} 100 \mathrm{nM}$

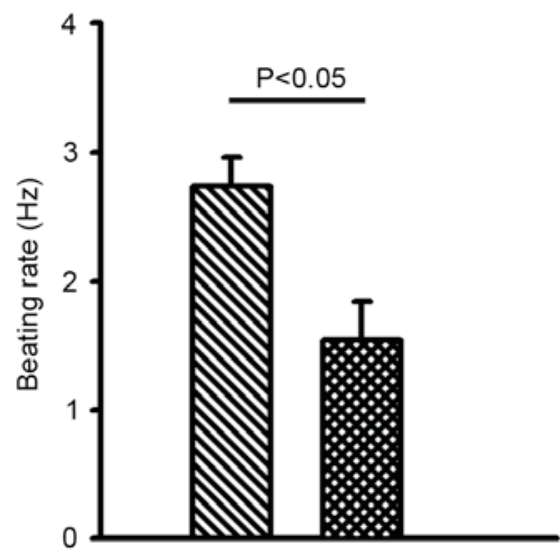

B
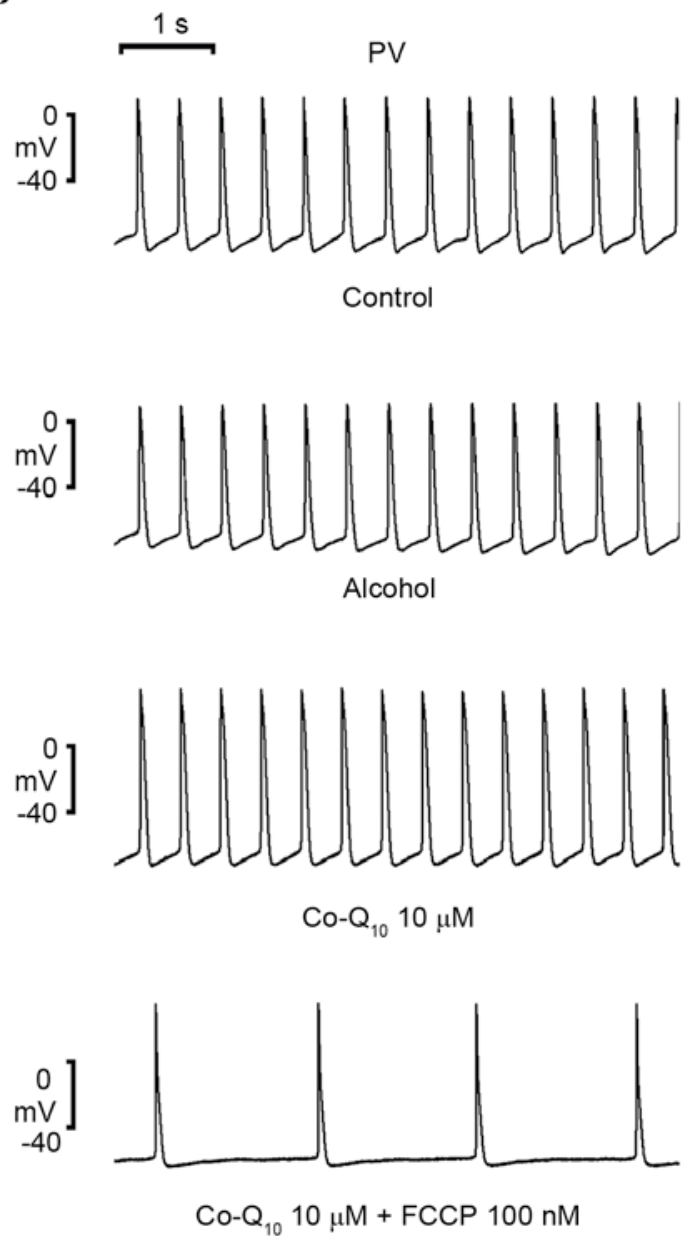

DN.

$\therefore$

$\mathrm{Co}_{10} 10 \mu \mathrm{M}$

Co- $Q_{10} 10 \mu M+F C C P 100 n M$

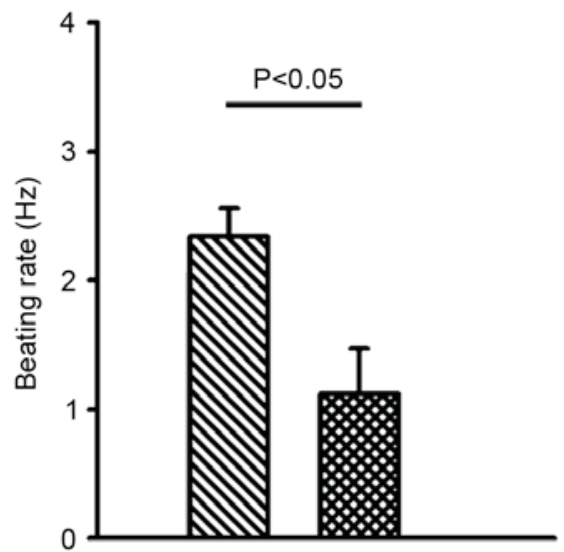

Figure 4. Effects of Co- $\mathrm{Q}_{10}$ and FCCP on SAN and PV with spontaneous activity. (A) SANs with spontaneous activity after Co- $\mathrm{Q}_{10}(10 \mu \mathrm{M})$ and Co- $\mathrm{Q}_{10}$ $(10 \mu \mathrm{M})+\mathrm{FCCP}(100 \mathrm{nM})$ administration, and average beating rate of SANs with spontaneous activity following Co- $\mathrm{Q}_{10}(10 \mu \mathrm{M})$ and Co-Q 10 (10 $\left.\mu \mathrm{M}\right)+\mathrm{FCCP}$ $(100 \mathrm{nM})$ administration. (B) PVs with spontaneous activity after Co- $\mathrm{Q}_{10}(10 \mu \mathrm{M})$ and Co- $\mathrm{Q}_{10}(10 \mu \mathrm{M})+\mathrm{FCCP}(100 \mathrm{nM})$ administration, and average beating rate of PVs with spontaneous activity following Co- $\mathrm{Q}_{10}(10 \mu \mathrm{M})$ and $\mathrm{Co}_{0}-\mathrm{Q}_{10}(10 \mu \mathrm{M})+\mathrm{FCCP}(100 \mathrm{nM})$ administration. Data are presented as the mean \pm standard error of the mean $(n=6)$. Co- $\mathrm{Q}_{10}$, coenzyme- $\mathrm{Q}_{10}$; FCCP, trifluorocarbonylcyanide phenylhydrazone; SANs, sinoatrial nodes; PVs, pulmonary veins.

ATP deficiency compared with PVs. Evidence suggests that sinus node dysfunction is able to facilitate the conditions for AF occurrence by increasing ectopy and dispersion of refractoriness $(23,26,27)$. Intact SAN electrical activity is able to suppress arrhythmogenesis from PVs through a constant overdrive of the PVs. The reverse overdrive of the PV on the 

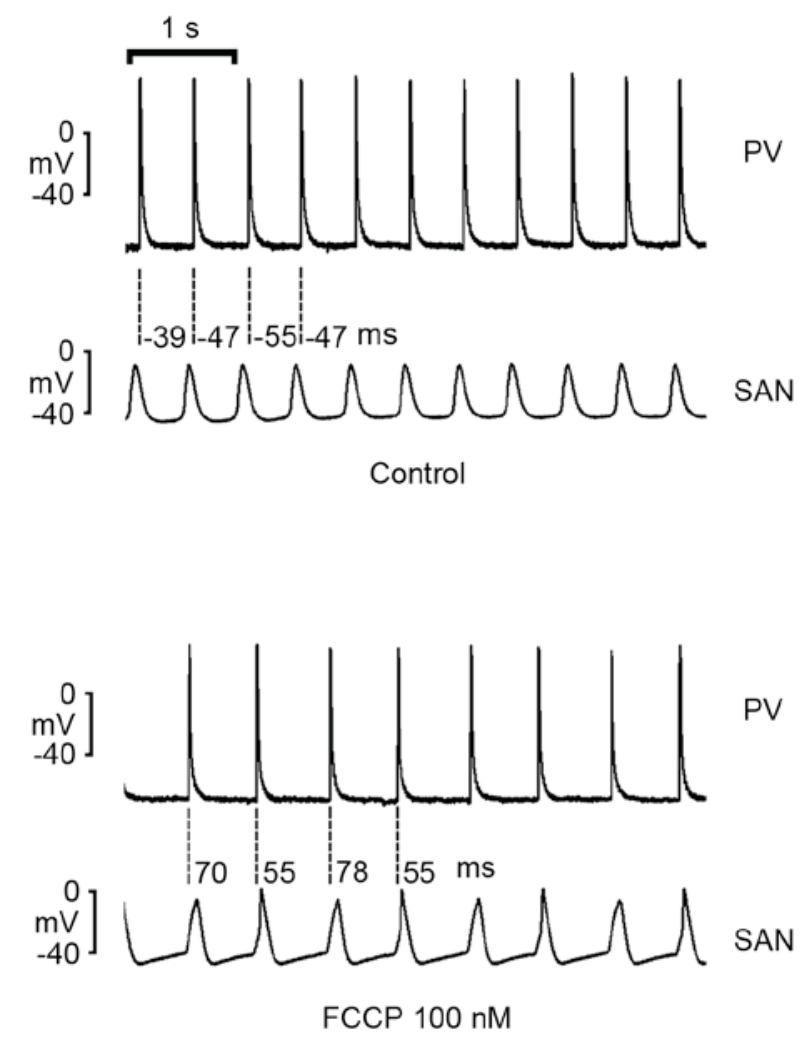

Figure 5. Effects of $100 \mathrm{nM} \mathrm{FCCP}$ on intact SAN-PV preparations. Schematic drawings of simultaneous recordings at the SAN and PV in intact SAN-PV preparations at the baseline (upper panel) and after application of $100 \mathrm{nM} \mathrm{FCCP} \mathrm{(lower} \mathrm{panel).} \mathrm{FCCP} \mathrm{at} 100 \mathrm{nM}$ induced a conduction direction shift from SAN-to-PV at the baseline to PV-to-SAN ( $\mathrm{n}=8)$. FCCP, trifluorocarbonylcyanide phenylhydrazone; SANs, sinoatrial nodes; PVs, pulmonary veins.

SAN caused by FCCP may facilitate the occurrence of PV arrhythmogenesis and contribute to mitochondrial dysfunction-related atrial arrhythmogenesis.

The results of the present study revealed that $\mathrm{Co}-\mathrm{Q}_{10}$ $(10 \mu \mathrm{M})$ may modulate mitochondrial dysfunction. The presence of $\mathrm{Co}-\mathrm{Q}_{10}$ led to similar FCCP-induced rate reductions in SANs and PVs, which suggests that the FCCP-induced $\mathrm{PV}$-overdrive-SAN conduction shift is attenuated by Co- $\mathrm{Q}_{10}$. A previous study demonstrated that the use of $\mathrm{Co}-\mathrm{Q}_{10}$ as adjuvant treatment in patients with heart failure may attenuate the incidence of AF (18), which may occur in part through the protective role of $\mathrm{Co}-\mathrm{Q}_{10}$ against mitochondrial dysfunction-induced PV arrhythmogenesis, as revealed in the present study. Co-Q $\mathrm{Q}_{10}$ promoted recovery of ATP following reoxygenation, which suggests that exogenous $\mathrm{Co}-\mathrm{Q}_{10}$ may facilitate resynthesis of ATP in functionally impaired mitochondria. Generation of APs in SAN cells is able to be maintained by a small quantity of ATP (28), which may be produced by exogenous $\mathrm{Co}-\mathrm{Q}_{10}$. A previous study demonstrated that $\mathrm{Co}-\mathrm{Q}_{10}$ did not prevent decreases in ATP in tissues in the initial period of hypoxia at 30-60 min; however, the ATP content at $120 \mathrm{~min}$ of hypoxia in the presence of $\mathrm{Co}-\mathrm{Q}_{10}$ was higher than that of the control (28), which may partially explain the failure of Co- $\mathrm{Q}_{10}$ to prevent FCCP-induced PV and SAN rate reductions.

In the present study, FCCP at $100 \mathrm{nM}$ shortened the APD and decreased contractility slightly in the RA and significantly in the LA. The influence of the mitochondrial energetic status on APs is mediated largely by $\mathrm{K}_{\text {ATP }}$ channels in the membrane. These findings are consistent with previous studies, whereas hypoxia or ischemia progressively shortens the APD caused by the opening of $\mathrm{K}_{\text {ATP }}$ channels (24). Discrepant effects of hypoxia on AP shortening between the RA and LA were observed in a rabbit model. Shortening the APD in the RA and LA provides a basis for AF persistence through facilitating the generation of atrial reentry circuits. The differential response of the RA and LA to FCCP may increase dispersions of the APD and may facilitate the maintenance of AF. Although the mechanisms underlying differences between the RA and LA are not clear, it is possible that higher expression levels of heat shock protein 70 in the RA may result in the lower sensitivity of the RA to FCCP (24).

There were some limitations to the present study. Firstly, administration of FCCP may produce a non-physiological condition of mitochondrial dysfunction. Secondly, an acute effect of mitochondrial dysfunction caused by FCCP application was observed in the present study, which may differ from the chronic effect of mitochondrial dysfunction. Finally, the present study used young, healthy tissue preparations and so results may differ in pathological settings.

In conclusion, mitochondrial dysfunction regulates electrophysiological characteristics of the PV, SAN, RA and LA, which may have a role in the pathophysiology of atrial arrhythmogenesis.

\section{Acknowledgements}

The present study was financially supported by grants from the Ministry of Science and Technology (grant nos. MOST1 
A

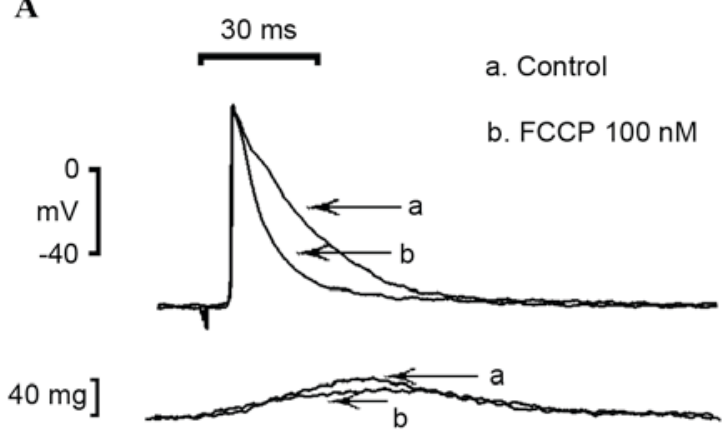

LA

口Control m $\mathrm{FCCP} 100 \mathrm{nM}$
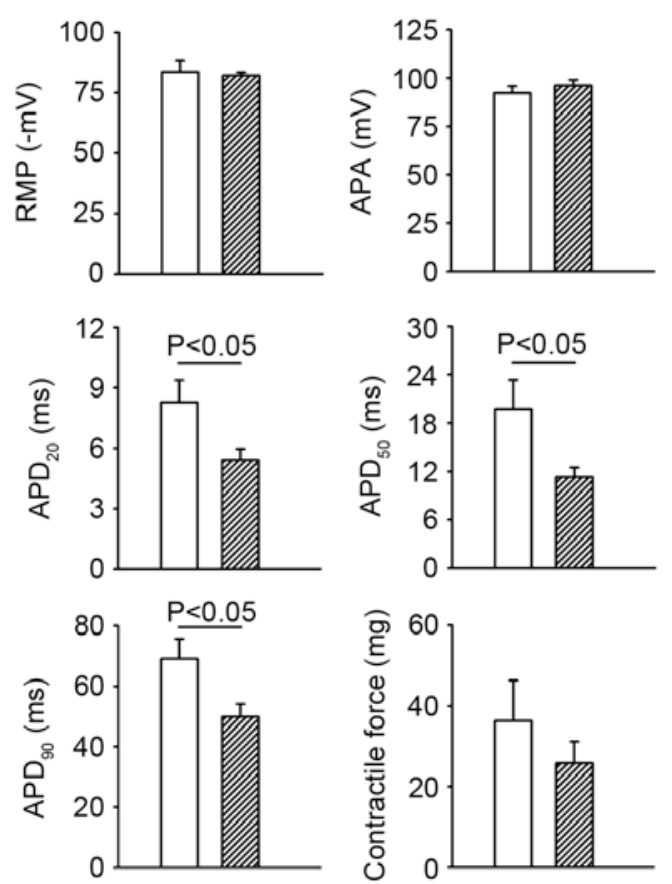

B

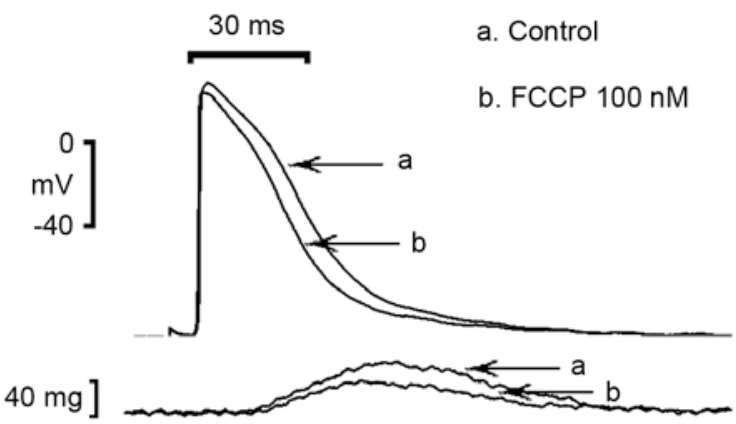

RA

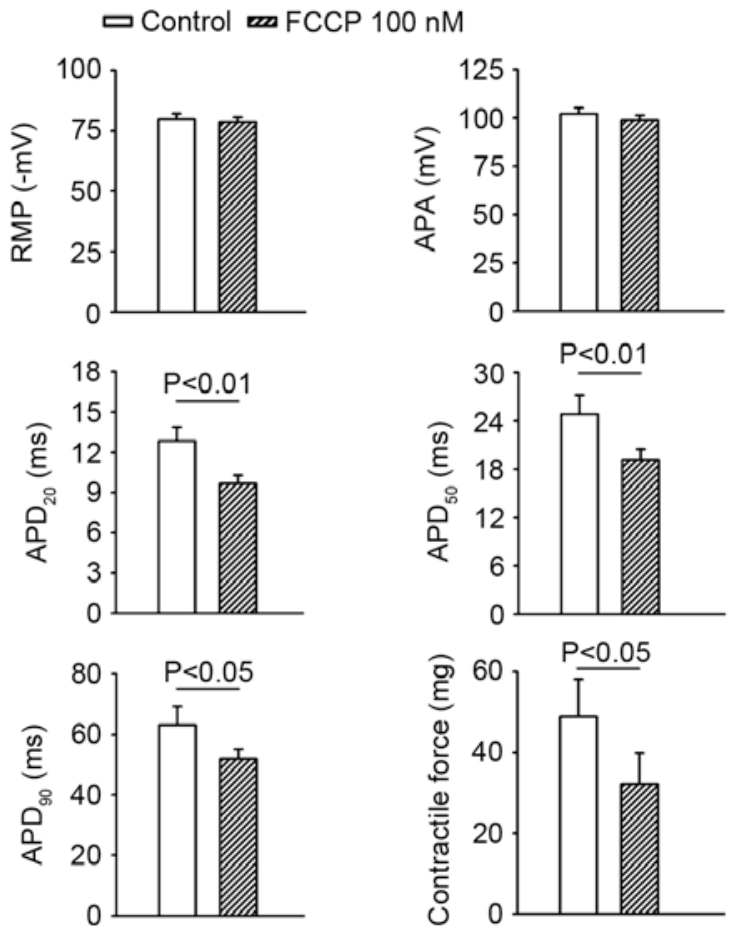

Figure 6. Effects of $100 \mathrm{nM} \mathrm{FCCP} \mathrm{on} \mathrm{electrophysiological} \mathrm{characteristics} \mathrm{of} \mathrm{the} \mathrm{LA} \mathrm{and} \mathrm{RA.} \mathrm{(A)} \mathrm{APs} \mathrm{at} \mathrm{the} \mathrm{baseline} \mathrm{and} \mathrm{after} 100 \mathrm{nM}$ FCCP. Average data of APs and contractility in the LA before and after administration of $100 \mathrm{nM} \mathrm{FCCP}(\mathrm{n}=5)$. (B) APs at the baseline and after $100 \mathrm{nM}$ FCCP. Average data of APs and contractility in the RA before and after administration of $100 \mathrm{nM} \mathrm{FCCP}(\mathrm{n}=6)$. Data are presented as the mean \pm standard error of the mean. FCCP, trifluorocarbonylcyanide phenylhydrazone; RA, right atrium; LA, left atrium; APs, action potentials; RMP, resting membrane potential; APA, action potential amplitude; $\mathrm{APD}_{20}$, AP duration measured at $20 \%$ repolarization of the amplitude; $\mathrm{APD}_{50}$, $\mathrm{AP}$ duration measured at $50 \%$ repolarization of the amplitude; $\mathrm{APD}_{90}$, AP duration measured at $90 \%$ repolarization of the amplitude.

03-2314-B-038-041-MY2, MOST103-2314-B-281-005-MY2, MOST103-2314-B-281-006, MOST103-2314-B-038-055, NSC102-2314-B-016-029-MY2,NSC102-2325-B-010-005 and NSC102-2628-B-038-002-MY3), Taipei Medical University (grant no. TMU101-AE1-B31), Taipei Medical University-Wan Fang Hospital (grant nos. 101-wf-eva-11, 101-wf-phd-01, 103swf05, 103-wf-eva-02, 104swf02 and 104-wf-eva-01) and Chi-Mei Medical Center (grant nos. 104CM-TMU-07 and CMNDMC10410) of Taiwan.

\section{References}

1. Tsang TS and Gersh BJ: Atrial fibrillation: An old disease, a new epidemic. Am J Med 113: 432-435, 2002.

2. Lin YK, Lin FZ, Chen YC, Cheng CC, Lin CI, Chen YJ and Chen SA: Oxidative stress on pulmonary vein and left atrium arrhythmogenesis. Circ J 74: 1547-1556, 2010.
3. Mihm MJ, Yu F, Carnes CA, Reiser PJ, McCarthy PM, Van Wagoner DR and Bauer JA: Impaired myofibrillar energetics and oxidative injury during human atrial fibrillation. Circulation 104: 174-180, 2001.

4. Wang X, Takeda S, Mochizuki S, Jindal R and Dhalla NS: Mechanisms of hydrogen peroxide-induced increase in intracellular calcium in cardiomyocytes. J Cardiovasc Pharmacol Ther 4: 41-48, 1999.

5. Van Wagoner DR: Redox modulation of cardiac electrical activity. J Cardiovasc Electrophysiol 12: 183-184, 2001.

6. Brown DA and O'Rourke B: Cardiac mitochondria and arrhythmias. Cardiovasc Res 88: 241-249, 2010.

7. Jeong EM, Liu M, Sturdy M, Gao G, Varghese ST, Sovari AA and Dudley SC Jr: Metabolic stress, reactive oxygen species, and arrhythmia. J Mol Cell Cardiol 52: 454-463, 2012.

8. Montaigne D, Marechal X, Lefebvre P, Modine T, Fayad G, Dehondt H, Hurt C, Coisne A, Koussa M, Remy-Jouet I, et al: Mitochondrial dysfunction as an arrhythmogenic substrate: A translational proof-of-concept study in patients with metabolic syndrome in whom post-operative atrial fibrillation develops. J Am Coll Cardiol 62: 1466-1473, 2013. 
9. Ozawa T: Genetic and functional changes in mitochondria associated with aging. Physiol Rev 77: 425-464, 1997.

10. Wei YH, Lu CY, Lee HC, Pang CY and Ma YS: Oxidative damage and mutation to mitochondrial DNA and age-dependent decline of mitochondrial respiratory function. Ann N Y Acad Sci 854: 155-170, 1998.

11. Michikawa Y, Mazzucchelli F, Bresolin N, Scarlato G and Attardi G: Aging-dependent large accumulation of point mutations in the human mtDNA control region for replication. Science 286: 774-779, 1999.

12. Wang $\mathrm{CH}, \mathrm{Wu} \mathrm{SB}, \mathrm{Wu} \mathrm{YT}$ and Wei $\mathrm{YH}$ : Oxidative stress response elicited by mitochondrial dysfunction: Implication in the pathophysiology of aging. Exp Biol Med (Maywood) 238: 450-460, 2013

13. Yoshida H, Bao L, Kefaloyianni E, Taskin E, Okorie U, Hong M, Dhar-Chowdhury P, Kaneko M and Coetzee WA: AMP-activated protein kinase connects cellular energy metabolism to KATP channel function. J Mol Cell Cardiol 52: 410-418, 2012.

14. Sasaki N, Sato T, Marbán E and O'Rourke B: ATP consumption by uncoupled mitochondria activates sarcolemmal K(ATP) channels in cardiac myocytes. Am J Physiol Heart Circ Physiol 280: H1882-H1888, 2001.

15. Liu M, Sanyal S, Gao G, Gurung IS, Zhu X, Gaconnet G, Kerchner LJ, Shang LL, Huang CL, Grace A, et al: Cardiac $\mathrm{Na}+$ current regulation by pyridine nucleotides. Circ Res 105 737-745, 2009.

16. Liu M, Liu H and Dudley SC Jr: Reactive oxygen species originating from mitochondria regulate the cardiac sodium channel. Circ Res 107: 967-974, 2010

17. Matejíková J1, Kucharská J, Pancza D and Ravingerová T: The effect of antioxidant treatment and NOS inhibition on the incidence of ischemia-induced arrhythmias in the diabetic rat heart. Physiol Res 57 (Suppl 2): S55-S60, 2008.

18. Zhao Q, Kebbati AH, Zhang Y, Tang Y, Okello E and Huang C: Effect of coenzyme Q10 on the incidence of atrial fibrillation in patients with heart failure. J Investig Med 63: 735-739, 2015.

19. Langsjoen PH and Langsjoen AM: Overview of the use of CoQ10 in cardiovascular disease. Biofactors 9: 273-284, 1999.
20. Honjo H, Boyett MR, Niwa R, Inada S, Yamamoto M, Mitsui K, Horiuchi T, Shibata N, Kamiya K and Kodama I: Pacing-induced spontaneous activity in myocardial sleeves of pulmonary veins after treatment with ryanodine. Circulation 107: 1937-1943, 2003.

21. Chen SA, Hsieh MH, Tai CT, Tsai CF, Prakash VS, Yu WC, Hsu TL, Ding YA and Chang MS: Initiation of atrial fibrillation by ectopic beats originating from the pulmonary veins: Electrophysiological characteristics, pharmacological responses, and effects of radiofrequency ablation. Circulation 100: 1879-1886, 1999.

22. Chen YJ, Chen SA, Chen YC, Yeh HI, Chan P, Chang MS and Lin CI: Effects of rapid atrial pacing on the arrhythmogenic activity of single cardiomyocytes from pulmonary veins: Implication in initiation of atrial fibrillation. Circulation 104: 2849-2854, 2001

23. Chen YC, Lu YY, Cheng CC, Lin YK, Chen SA and Chen YJ: Sinoatrial node electrical activity modulates pulmonary vein arrhythmogenesis. Int J Cardiol 173: 447-452, 2014.

24. Lin YK, Lai MS, Chen YC, Cheng CC, Huang JH, Chen SA, Chen YJ and Lin CI: Hypoxia and reoxygenation modulate the arrhythmogenic activity of the pulmonary vein and atrium. Clin Sci (Lond) 122: 121-132, 2012.

25. Senges J, Mizutani T, Pelzer D, Brachmann J, Sonnhof U and Kübler W: Effect of hypoxia on the sinoatrial node, atrium and atrioventricular node in the rabbit heart. Circ Res 44: 856-863, 1979.

26. Luck JC and Engel TR: Dispersion of atrial refractoriness in patients with sinus node dysfunction. Circulation 60: 404-412, 1979.

27. Loomis TA and Krop S: Auricular fibrillation induced and maintained in animals by acetylcholine or vagal stimulation. Circ Res 3: 390-396, 1955.

28. Yoshikawa Y, Kano T, Higuchi $M$ and Nishi K: Effects of coenzyme Q10 on recovery of hypoxia-induced changes in ATP and creatine phosphate contents of sinoatrial nodal cells of the rabbit's heart after reoxygenation. Arch Int Pharmacodyn Ther 287: 96-108S, 1987. 